Psychological Medicine

http://journals.cambridge.org/PSM

Additional services for Psychological Medicine:

PSYCHOLOGICAL

Email alerts: $\underline{\text { Click here }}$

Subscriptions: $\underline{\text { Click here }}$

Commercial reprints: $\underline{\text { Click here }}$

Terms of use : $\underline{\text { Click here }}$

\title{
Persistence of cognitive impairment and its negative impact on psychosocial functioning in lithium-treated, euthymic bipolar patients: a 6-year follow-up study
}

\author{
E. Mora, M. J. Portella, I. Forcada, E. Vieta and M. Mur
}

Psychological Medicine / Volume 43 / Issue 06 / June 2013, pp 1187 - 1196

DOI: 10.1017/S0033291712001948, Published online: 31 August 2012

Link to this article: http://journals.cambridge.org/abstract_S0033291712001948

How to cite this article:

E. Mora, M. J. Portella, I. Forcada, E. Vieta and M. Mur (2013). Persistence of cognitive impairment and its negative impact on psychosocial functioning in lithium-treated, euthymic bipolar patients: a 6-year follow-up study. Psychological Medicine, 43, pp 1187-1196 doi:10.1017/S0033291712001948

Request Permissions : $\underline{\text { Click here }}$ 


\title{
Persistence of cognitive impairment and its negative impact on psychosocial functioning in lithium-treated, euthymic bipolar patients: a 6-year follow-up study
}

\author{
E. Mora ${ }^{1}$, M. J. Portella ${ }^{2}$, I. Forcada ${ }^{1}$, E. Vieta ${ }^{3}$ and M. Mur ${ }^{1 *}$ \\ ${ }^{1}$ Psychiatric Service, Hospital Santa Maria, University of Lleida, IRBLleida (Biomedicine Research Institute), Lleida, Spain \\ ${ }^{2}$ Psychiatric Service, Research Institute, Hospital de Santa Creu i Sant Pau, Autonomous University of Barcelona, Barcelona, Spain \\ ${ }^{3}$ Bipolar Disorders Program, Hospital Clínic, University of Barcelona, IDIBAPS, CIBERSAM, Barcelona, Spain
}

Background. Previous cross-sectional studies report that cognitive impairment is associated with poor psychosocial functioning in euthymic bipolar patients. There is a lack of long-term studies to determine the course of cognitive impairment and its impact on functional outcome.

\begin{abstract}
Method. A total of 54 subjects were assessed at baseline and 6 years later; 28 had DSM-IV TR bipolar I or II disorder (recruited, at baseline, from a Lithium Clinic Program) and 26 were healthy matched controls. They were all assessed with a cognitive battery tapping into the main cognitive domains (executive function, attention, processing speed, verbal memory and visual memory) twice over a 6-year follow-up period. All patients were euthymic (Hamilton Rating Scale for Depression score lower than 8 and Young mania rating scale score lower than 6) for at least 3 months before both evaluations. At the end of follow-up, psychosocial functioning was also evaluated by means of the Functioning Assessment Short Test.

Results. Repeated-measures multivariate analysis of covariance showed that there were main effects of group in the executive domain, in the inhibition domain, in the processing speed domain, and in the verbal memory domain $(p<0.04)$. Among the clinical factors, only longer illness duration was significantly related to slow processing $(p=0.01)$, whereas strong relationships were observed between impoverished cognition along time and poorer psychosocial functioning $(p<0.05)$.

Conclusions. Executive functioning, inhibition, processing speed and verbal memory were impaired in euthymic bipolar out-patients. Although cognitive deficits remained stable on average throughout the follow-up, they had enduring negative effects on psychosocial adaptation of patients.
\end{abstract}

Received 16 March 2012; Revised 15 July 2012; Accepted 20 July 2012 ; First published online 31 August 2012

Key words: Bipolar disorder, cognition, follow-up study, lithium treatment, psychosocial functioning.

\section{Introduction}

A considerable amount of evidence has confirmed that neuropsychological functioning is impaired in individuals with bipolar disorder, not only during acute episodes but also during periods of remission of affective symptoms, namely euthymic states (Torres et al. 2007). Despite current evidence, the neuropsychological profile during euthymia has not yet been well established and substantial heterogeneity has been reported (Mann-Wrobel et al. 2011). Emerging data suggest that patients with bipolar disorder exhibit cognitive impairment in attention,

\footnotetext{
* Address for correspondence: M. Mur, M.D., Ph.D., Servei de Psiquiatria, Hospital Santa Maria, C/Rovira Roure, 44, 25198 Lleida, Catalunya, Spain.

(Email: mmur@gss.scs.es)
}

verbal memory and executive functioning during remission (Martínez-Arán et al. 2004b; Mur et al. 2007; Torres et al. 2007; Mann-Wrobel et al. 2011). Several studies reveal that it is important to examine cognitive performance in euthymic bipolar disorder patients since there is a strong association between neuropsychological impairment and poor psychosocial functioning outcome (Wingo et al. 2009).

Most of the previous studies on neurocognition and its functional impact in euthymic patients are crosssectional. Since bipolar disorder is a chronic and recurrent disease it is necessary to proceed examining longitudinally the cognitive and functional course of these individuals in order to clarify the particular nature and specificity of the reported deficits and how these can change over time (Robinson \& Ferrier, 2006). There is an actual lack of longitudinal studies in the current literature foreclosing the possibility to 
determine the evolution of cognition (BalanzáMartínez et al. 2005; Burdick et al. 2006; Mur et al. 2008; Tabarés-Seisdedos et al. 2008) and psychosocial functioning (Martino et al. 2009; Bonnín et al. 2010; Burdick et al. 2010) in euthymic bipolar patients. Furthermore, the cognitive follow-up of these patients becomes crucial for providing tools to administer the most suitable pharmacological and psychosocial treatment strategies (Gildengers et al. 2009).

The aim of the present study is to investigate the longitudinal neuropsychological profile of euthymic bipolar out-patients compared with healthy matched controls in a 6-year period of follow-up and to examine the psychosocial disabilities as related to cognitive deficits. An important methodological feature of this study, as compared with the very few previous studies that looked at this issue, is that healthy control subjects were also assessed at baseline and 6 years later, controlling for the effects of time and ageing. We hypothesized that the cognitive deficits would remain stable regardless of the clinical course of the illness, and this impairment would be related to the psychosocial adaptation at the end of the follow-up.

\section{Method}

\section{Subjects}

A total of 28 euthymic bipolar patients and 26 healthy matched controls were admitted into the study and were evaluated at baseline and 6 years later with a clinical interview, biochemical tests and a neuropsychological battery. On average, the endpoint (T2) occurred 6.1 years after baseline (T1) (range 8.2-4.9 years) and was conducted by the same neuropsychologist. The Local Ethics Committee approved the study, and written informed consent was obtained from all participants (patients and healthy controls).

The patient sample was obtained from the Lithium Clinic Program at Hospital Santa Maria, Lleida, in 2003. Inclusion criteria included being on lithium treatment at T1, aged between 18 and 65 years, fulfilling Diagnostic and Statistical Manual of Mental Disorders, fourth edition, text revision (DSM-IV-TR) criteria for bipolar disorder, and being in remission for at least 3 months (Mur et al. 2007). Following previous studies (Robinson et al. 2006), patients were characterized as euthymic if they had a total 17-item Hamilton Rating Scale for Depression (HAMD; Hamilton, 1960) score below 8 and a total Young Mania Rating Scale (YMRS; Young et al. 1978) score below 6 for at least 3 months at the time of assessment. Exclusion criteria were the following: significant physical or neurological illness, substance abuse or dependence in the last 12 months, electroconvulsive therapy in the preceding year. At the endpoint, patients had to fulfil the same inclusion and exclusion criteria, except for medication that was allowed to be changed during the 6 years, if clinically needed. Therefore, at follow-up, all subjects were retested if they had been euthymic for at least 3 months, as confirmed by the criteria as at baseline.

A total of 26 healthy controls from the same geographic area, matched in terms of gender, age and years of education were recruited via advertisements and from non-medical hospital staff. Controls had no current or past psychiatric history, as determined by the Structured Clinical Interview for DSM-IV Axis I Disorders. They had no first-degree relatives with bipolar or psychotic diagnoses. Controls were subject to the same exclusion criteria and were assessed with the same full study protocol as the patients. They were also evaluated twice (at baseline and 6 years later).

\section{Demographic, clinical and pharmacological data}

Demographic variables for euthymic bipolar patients and healthy controls were age, gender, years of education and family history of mental illness. Clinical variables were obtained from the sample of bipolar patients, including: age at illness onset, number of prior manic episodes and hospitalizations, period of stabilization (years), history of psychotic symptoms, seasonal pattern, suicide attempts and bipolar subtype (I or II). Biochemical tests were performed on all patients, including for thyroid function, serum lithium levels and urine drug testing.

With respect to pharmacological variables, at baseline, T1, 14 patients were receiving lithium as monotherapy and the other 14 were on combination treatment (lithium plus antidepressants and/or antipsychotics). Lithium dosages at T1 were 820$1380 \mathrm{mg} /$ day (serum lithium levels $0.46-0.86 \mathrm{mmol} / 1$; treatment duration 1-10 years). At the study endpoint, T2, two patients were drug-free, 10 were receiving lithium monotherapy, 11 were on combination treatment (lithium dosage 916-1388 mg/day; serum lithium levels $0.51-0.71 \mathrm{mmol} / 1$; treatment duration 5-15 years); and five were receiving other psychopharmacological treatments (two were receiving other mood stabilizers, one was on a combination of antidepressant and antipsychotic, another one was receiving another mood stabilizer plus antidepressant and the other was on another mood stabilizer plus antipsychotic).

\section{Neuropsychological assessment}

To provide a more general pattern of cognitive performance, this battery included neuropsychological 
tests that tapped into broad cognitive categories as documented in previous literature (Mur et al. 2007). The estimated mean intelligence quotient (IQ) of the subjects was obtained from the weighted scores of the Vocabulary and Block Design subtests of the Wechsler Adult Intelligence Scale (WAIS-III; Wechsler, 2001), because these two scores are the most highly correlated with total IQ. The instruments administered were:

(i) Vocabulary, Block Design and Digits Subtests from WAIS-III (Wechsler, 2001);

(ii) Wisconsin Card Sorting Test (WCST; Heaton, 1981);

(iii) Stroop Colour and Word Test (Spreen \& Strauss, 1998);

(iv) Verbal fluency task of the Controlled Oral Word Association Test/Categories (FAS; Spreen \& Strauss, 1998);

(v) Trail Making Test (TMT), part A (TMT-A) and part B (TMT-B) (Reitan, 1958);

(vi) Conners' Continuous Performance Test II (CPTII; Conners, 2000);

(vii) California Verbal Learning Test (CVLT; Delis et al. 1987);

(viii) Rey Complex Figure Test (RCFT; Meyers \& Meyers, 1995).

\section{Psychosocial functioning}

At baseline, to obtain information about global activity, patients and controls were assessed with the Global Assessment of Functioning scale. Moreover, occupational functioning was specifically assessed and defined as follows: active (subjects with a full- or part-time job, students and housewives), inactive (unemployed subjects and those with temporary sick leave) and retired (permanent sick leave or retired subjects). At the endpoint, another scale was also administered in order to evaluate psychosocial functioning more accurately. The Functioning Assessment Short Test (FAST; Rosa et al. 2007) is more appropriate since it takes into consideration different domains and it is more specific for assessing different levels of functioning in bipolar disorder. Its 24 items of the scale are divided into six specific areas of functioning: autonomy, occupational functioning, cognitive functioning, financial issues, interpersonal relationships and leisure time. Therefore, subscores can be obtained from these areas as well as a total score.

\section{Statistical procedures}

Data analyses were carried out with the statistical package SPSS for Windows, version 15.0 (SPSS Inc., USA). Differences between groups in demographic, psychosocial and clinical variables were assessed with a univariate analysis of variance, by examining a single factor of group (out-patients versus healthy controls) at T1 and at T2; and paired two-sample $t$ tests were used to assess time differences for such variables. Non-quantitative variables were examined by means of non-parametric tests.

Neuropsychological tasks were sorted by cognitive domains: executive functions, attention, processing speed, verbal memory and visual memory (Mur et al. 2008). Performance on neuropsychological tasks was compared across the two groups by means of separate multivariate repeated-measures analyses of covariance (MANCOVA) for each cognitive domain. Estimated pre-morbid IQ, YMRS and HAMD scores were included as covariates since they showed significant differences between groups at T2, as shown in Table 2 . The cognitive variables that did not meet the criterion of normality were excluded from the multivariate analyses: CVLT recognition, number of perseverative errors at CPT-II and number of categories of WCST. No other analyses were carried out with these latter variables as the cognitive domains were already sufficiently explored with other neuropsychological tests.

In order to establish correlations between cognitive changes in neuropsychological performance after 6 years in bipolar patients with clinical and functional variables, the difference between scores at T2 and T1 was calculated for those variables that showed significant differences between groups. Therefore new variables that reflected performance decrement or increment across time were obtained ( $\Delta$ Digit backward, $\Delta$ TMT-B, $\triangle$ TMT-A, $\triangle$ CVLT immediate recall, $\triangle$ CVLT delayed recall, $\Delta$ Stroop Inhibition and $\Delta$ Hit Reaction Time in CPT-II). Then, associations between cognitive changes and clinical and functional variables were analysed with partial correlations by controlling for low-level depressive symptoms (HAMD) as shown in Table 3.

\section{Results}

\section{Demographic, clinical and functional results}

Demographic, clinical and pharmacological variables of the euthymic bipolar patients and healthy controls are displayed in Table 1 for the two time points (T1 and T2). Both groups of participants were matched in terms of age and gender. At T1, estimated premorbid IQ showed differences between the groups $\left(F_{1,52}=10.06, p=0.003\right)$ although it was not clinically relevant as all scores were situated within the range of $100 \pm 15$, not exceeding the limits of normality. In terms of work status, the groups displayed significant differences $\left[\chi^{2}=8.4\right.$, degrees of freedom $(\mathrm{df})=1$, 
Table 1. Demographic, clinical and pharmacological variables at $\mathrm{T} 1$ and $\mathrm{T} 2$

\begin{tabular}{|c|c|c|c|c|}
\hline \multirow[b]{2}{*}{ Variable } & \multicolumn{2}{|c|}{ Bipolar patients $(n=28)$} & \multicolumn{2}{|c|}{ Healthy controls $(n=26)$} \\
\hline & $\mathrm{T} 1$ & $\mathrm{~T} 2$ & $\mathrm{~T} 1$ & $\mathrm{~T} 2$ \\
\hline Mean age, years (S.D.) & $41.71(12.4)$ & $46.71(13)$ & $41.38(12.1)$ & $47.81(12.2)$ \\
\hline Mean years of education (s.D.) & $10.1(2.5)$ & $10.1(2.5)$ & $12.2(3.3)$ & $12.5(3.2)$ \\
\hline Mean estimated pre-morbid IQ (S.D.) & $97.8(11.8)$ & $102.2(12.3)$ & $107.3(10.2)$ & $111.1(9.7)$ \\
\hline Mean YMRS score (S.D.) & $1.64(1.9)$ & $1(1.3)$ & $0.62(0.9)$ & $0.5(1)$ \\
\hline Mean HAMD score (S.D.) & $1.46(1.7)$ & $2.11(2.2)$ & $1.23(1.1)$ & $0.62(1.2)$ \\
\hline Mean GAF score (s.D.) & $72.32(10.1)$ & $72.86(9.7)$ & $92.4(3.9)$ & \\
\hline Mean age at onset, years (s.D.) & $22.39(9.4)$ & $22.39(9.4)$ & & \\
\hline Mean number of hospitalizations (S.D.) & $3.04(2.4)$ & $3.64(2.9)$ & & \\
\hline Mean total number of manic episodes (S.D.) & $2.54(2.1)$ & $3.14(2.9)$ & & \\
\hline Mean years of stabilization (s.D.) & $3.18(3.2)$ & $7.11(5.2)$ & & \\
\hline Mean duration of illness, years (S.D.) & $18.43(13.5)$ & $24.29(13.5)$ & & \\
\hline Mean years of lithium treatment (S.D.) & $5.33(4.4)$ & $10(4.9)$ & & \\
\hline Mean serum lithium levels, mmol/1 (S.D.) & $0.66(0.2)$ & $0.71(0.2) / 21$ & & \\
\hline Mean lithium dosage, $\mathrm{mg} / \mathrm{d}$ (s.D.) & $1100(280)$ & $1152(236) / 21$ & & \\
\hline Gender, number of males (\%) & $14(50)$ & & $12(46.2)$ & \\
\hline \multicolumn{5}{|l|}{ Current work status, $n(\%)$} \\
\hline Active & $14(50)$ & $13(46.4)$ & $23(88.5)$ & $22(84.6)$ \\
\hline Inactive & $4(14.3)$ & $2(7.2)$ & $1(3.8)$ & 0 \\
\hline Retired/disabled & $10(35.7)$ & $13(46.4)$ & $2(7.7)$ & $4(15.4)$ \\
\hline Positive family history of mental illness, $n(\%)$ & $21(75)$ & $21(75)$ & $6(23.1)$ & $6(23.1)$ \\
\hline Lifetime history of psychotic symptoms, $n(\%)$ & $22(78.6)$ & $22(78.6)$ & & \\
\hline Lifetime history of seasonal pattern, $n(\%)$ & $17(60.7)$ & $17(60.7)$ & & \\
\hline Personal history of suicide attempts, $n(\%)$ & $14(50)$ & $16(57.1)$ & & \\
\hline \multicolumn{5}{|l|}{ Diagnosis, $n(\%)$} \\
\hline Bipolar I disorder & $19(67.9)$ & $19(67.9)$ & & \\
\hline Bipolar II disorder & $9(32.1)$ & $9(32.1)$ & & \\
\hline \multicolumn{5}{|l|}{ Type of current medication, $n(\%)$} \\
\hline Lithium monotherapy & $14(50)$ & $10(35.7)$ & & \\
\hline Lithium + combination & $14(50)$ & $11(39.3)$ & & \\
\hline Others & & $5(17.9)$ & & \\
\hline None & & $2(7.1)$ & & \\
\hline
\end{tabular}

T1, Baseline; T2, 6-year endpoint; S.D., standard deviation; IQ, intelligence quotient; YMRS, Young Mania Rating Scale; HAMD, Hamilton Rating Scale for Depression; GAF, Global Assessment of Functioning.

$p=0.004]$; the bipolar patients were less active and more retired than the healthy controls. With regard to subclinical symptomatology, YMRS score also differed between the two groups $\left(F_{1,52}=6.24, p=0.016\right)$, but HAMD score did not differ $\left(F_{1,52}=0.36, p>0.05\right)$. At $\mathrm{T} 2$, 6 years later, the bipolar euthymic patients and healthy controls also differed in estimated IQ $\left(F_{1,52}=8.52, p=0.005\right)$ and work status $\left(\chi^{2}=7.4, \mathrm{df}=1\right.$, $p=0.006)$. On this occasion, they differed in HAMD score $\left(F_{1,52}=9.24, p=0.004\right)$, but not in YMRS score $\left(F_{1,52}=2.49, p>0.05\right)$. None of the participants showed any evidence of clinical abnormality as checked with biochemical tests.

The group of bipolar patients exhibited significant worsening along the 6-year follow-up in their work status $\left(\chi^{2}=11.3, \mathrm{df}=1, p=0.001\right)$ and in subsyndromal depressive symptoms, measured by HAMD score $(t=0.45, p=0.016)$. At the endpoint, illness duration was of 24 years and patients had been stable for 7 years on average. However, during the study period 12 out of 28 patients $(42.9 \%)$ suffered relapses: six patients $(21.4 \%)$ suffered one or two episodes and the rest $(21.4 \%)$ suffered more than two episodes. These episodes were clinically characterized as follows: 16 were depressive, seven mixed, 10 manic and two hypomanic.

\section{Neuropsychological performance}

All neuropsychological variables included in each cognitive domain are listed in Table 2. As can be observed, after controlling for estimated pre-morbid 
Table 2. Neuropsychological results at $\mathrm{T} 1$ and $\mathrm{T} 2$ for all participants

\begin{tabular}{|c|c|c|c|c|c|c|c|c|}
\hline \multirow[b]{2}{*}{ Test } & \multicolumn{2}{|c|}{ Bipolar patients } & \multicolumn{2}{|c|}{ Healthy controls } & \multicolumn{4}{|c|}{ Statistical analysis } \\
\hline & $\mathrm{T} 1$ & $\mathrm{~T} 2$ & $\mathrm{~T} 1$ & $\mathrm{~T} 2$ & $\mathrm{~F}$ & $\mathrm{df}$ & $p^{\mathrm{a}}$ & $p^{\mathrm{b}}$ \\
\hline Executive test & & & & & $1.96^{\mathrm{c}}$ & 3,42 & N.S. & N.S. \\
\hline TMT part B & $82.96(27.7)$ & $102.7(50.1)$ & $55.9(22.1)$ & $55.7(20.0)$ & $7.1^{\mathrm{d}}$ & 1,44 & 0.006 & 0.008 \\
\hline FAS & $38.1(12.2)$ & $37.0(12.8)$ & $44.1(9.4)$ & $43.7(10.1)$ & $0.8^{\mathrm{d}}$ & 1,44 & N.s. & N.s. \\
\hline WAIS-III digit span backward & $5.1(1.7)$ & $4.9(1.8)$ & $6.5(1.9)$ & $6.6(1.6)$ & $7.0^{\mathrm{d}}$ & 1,44 & 0.008 & 0.012 \\
\hline Inhibition & & & & & $0.46^{\mathrm{c}}$ & 2,46 & N.S. & N.S. \\
\hline Stroop inhibition & $35.93(10.9)$ & $33.93(12.4)$ & $44.32(6.2)$ & $43.18(8.2)$ & $7.82^{\mathrm{d}}$ & 1,47 & 0.004 & 0.011 \\
\hline No. of perseverative errors WCST & $26.68(21.1)$ & $21.71(14.5)$ & $18.27(12.7)$ & $11.73(11.1)$ & $2.05^{\mathrm{d}}$ & 1,47 & N.s. & N.S. \\
\hline Attention & & & & & $2.6^{\mathrm{c}}$ & 3,45 & N.S. & N.S. \\
\hline Stroop interference & $-0.70(6.6)$ & $1.11(7.7)$ & $0.82(4.7)$ & $3.9(7.8)$ & $0.95^{\mathrm{d}}$ & 1,47 & N.S. & N.S. \\
\hline WAIS-III digit span forward & $7.5(1.9)$ & $7.5(1.8)$ & $8.9(2)$ & $8.6(2.1)$ & $2.80^{\mathrm{d}}$ & 1,47 & N.S. & N.S. \\
\hline CPT-II detectability, $\mathrm{d}^{\prime}$ & $0.97(0.5)$ & $0.87(0.4)$ & $0.87(0.5)$ & $1.1(0.4)$ & $0.08^{\mathrm{d}}$ & 1,47 & N.S. & N.S. \\
\hline Processing speed & & & & & $0.27^{c}$ & 2,46 & N.S. & N.S. \\
\hline TMT part A, ms & $45.89(21.5)$ & $47.75(22.23)$ & $29.73(16.5)$ & $28.23(10.5)$ & $6.54^{\mathrm{d}}$ & 1,47 & 0.009 & 0.030 \\
\hline CPT-II hit reaction time, $\mathrm{ms}$ & $474.2(75.6)$ & $492.8(112)$ & $423.6(68.1)$ & $425.4(66.3)$ & $6.52^{\mathrm{d}}$ & 1,47 & 0.022 & N.s. 0.079 \\
\hline Verbal memory & & & & & $4.53^{c}$ & 4,44 & 0.024 & 0.049 \\
\hline CVLT first trial & $6.75(1.8)$ & $6.11(2)$ & $6.55(1.3)$ & $7.59(1.9)$ & $0.88^{\mathrm{d}}$ & 1,47 & N.s. & N.S. \\
\hline CVLT total words & $51.5(10)$ & $49.36(12.1)$ & $54.86(5.8)$ & $57.68(7.3)$ & $3.59^{\mathrm{d}}$ & 1,47 & N.s. 0.052 & N.S. \\
\hline CVLT immediate recall & $10.68(2.7)$ & $10.64(3.1)$ & $11.5(2.2)$ & $13.45(1.6)$ & $5.26^{\mathrm{d}}$ & 1,47 & 0.008 & 0.013 \\
\hline CVLT delayed recall & $11.07(2.5)$ & $11.21(3.1)$ & $12.32(2.1)$ & $14.09(1.5)$ & $6.57^{\mathrm{d}}$ & 1,47 & 0.009 & 0.028 \\
\hline Visual memory & & & & & $1.39^{c}$ & 2,44 & N.S. & N.S. \\
\hline RCFT immediate recall & $19.33(6.6)$ & $19.6(6)$ & $23.34(4.7)$ & $23.41(4.6)$ & $4.19^{\mathrm{d}}$ & 1,45 & N.S. & N.s. \\
\hline RCFT delayed recall & $18.38(6.1)$ & $20.71(6.2)$ & $22.7(5.2)$ & $23.3(5.4)$ & $1.88^{\mathrm{d}}$ & 1,45 & N.S. & N.S. \\
\hline
\end{tabular}

Data are given as mean (standard deviation).

T1, Baseline; T2, 6-year endpoint; df, degrees of freedom; N.S., not significant; TMT, Trail Making Test; FAS, verbal fluency task of the Controlled Oral Word Association Test; WAIS-III, Wechsler Adult Intelligence Scale-III; WCST, Wisconsin Card Sorting Test; CPT-II, Continuous Performance Test II; CVLT, California Verbal Learning Test; RCFT, Rey Complex Figure Test; MANCOVA, multivariate repeated-measures analyses of covariance; IQ, intelligence quotient; HAMD, Hamilton Rating Scale for Depression; YMRS, Young Mania Rating Scale.

a Probability of repeated-measures MANCOVA controlling for IQ.

${ }^{\mathrm{b}}$ Probability of repeated-measures MANCOVA controlling for IQ, HAMD and YMRS.

${ }^{\mathrm{c}}$ Repeated-measures MANCOVA multivariate effects for each cognitive domain (group $\times$ time interactions).

${ }^{\mathrm{d}}$ Repeated-measures MANCOVA main effects of group (test of between-subjects effects).

IQ, the repeated-measures MANCOVA showed no significant interactions of time (T1 versus T2) by group (patients versus healthy controls) except in the verbal memory domain. By contrast, there were main effects of group in the executive domain (TMT-B and digit span backward), in the inhibition domain (Stroop inhibition), in the processing speed domain (TMT-A and hit reaction time of CPT-II), and finally in the verbal memory domain (immediate and delayed recall). Since previous studies (Clark et al. 2002; MartínezArán et al. 2004a; Savitz et al. 2005; Kurtz \& Gerraty, 2009) have already established the impact of residual mood symptoms, a repeated-measures MANCOVA was also performed, controlling for pre-morbid IQ and by YMRS and HAMD score. Even including these covariates, the results showed again the same effects, except for the interaction in the hit reaction time of CPT-II (although it depicted a similar trend), which did not reach the significance threshold. Significant group effects are presented in Fig. 1. Given that five patients were not on lithium treatment at $\mathrm{T} 2$, data were reanalysed excluding those individuals and the results were statistically similar to the whole sample results (data not shown) which might indicate that even when the medication regimen is less homogeneous, cognitive performance is statistically equivalent.

\section{Association results}

Relationships between cognitive impairment across time and clinical and functional variables in bipolar 


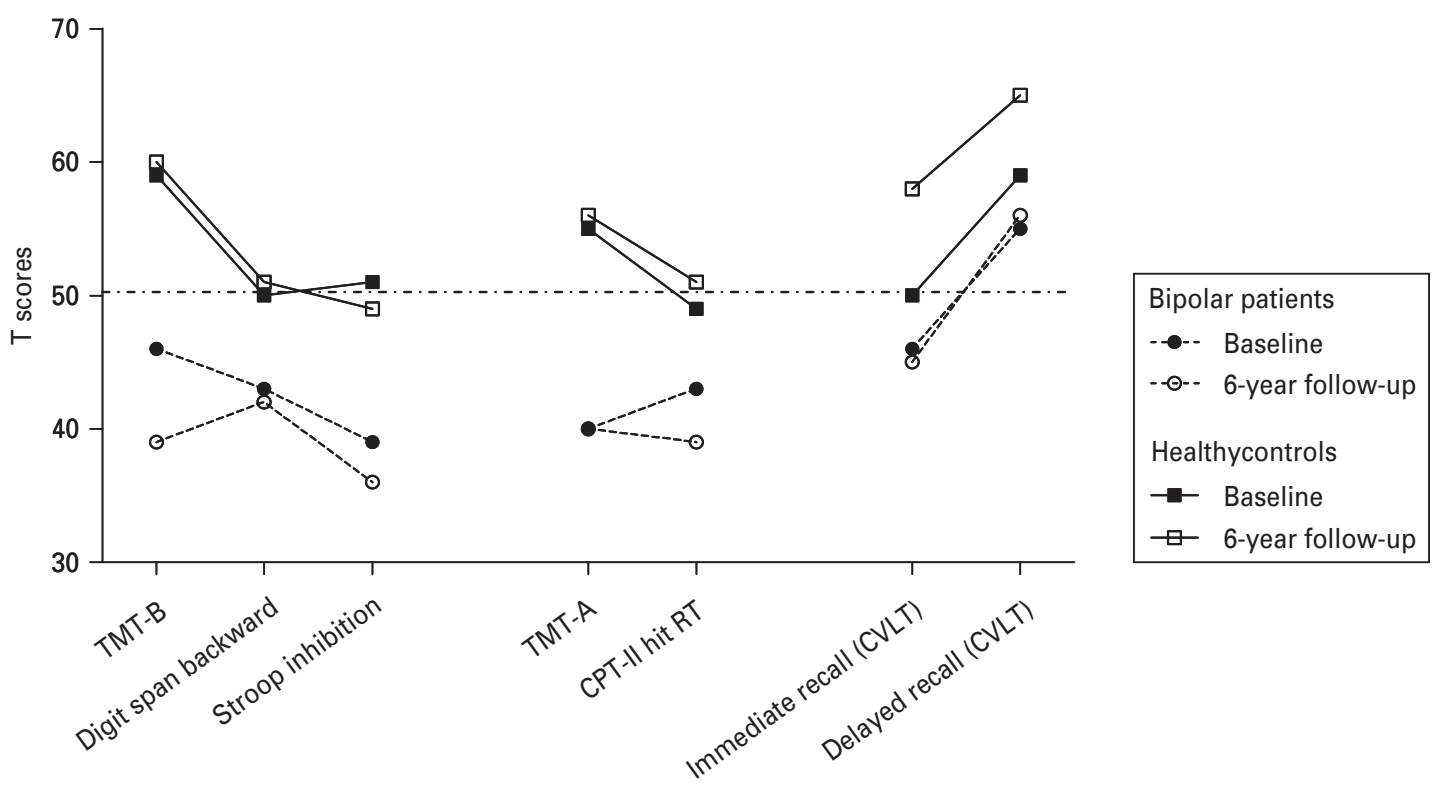

Fig. 1. Neuropsychological performance of the two groups (patients and healthy controls) at two time points (baseline and 6-year endpoint) for those tests that showed group effects in the multivariate repeated-measures analyses. Raw scores were transformed into $t$ scores from normative data for adult subjects. Transformation makes the comparison among tests more easily understandable. TMT, Trail Making Test; CPT-II, Continuous Performance Test II; RT, reaction time; CVLT, California Verbal Learning Test.

patients can be seen in Table 3. Clinical characteristics at the endpoint were not related to a worsening in neuropsychological results, with the exception of duration of illness that showed a significant correlation with hit reaction time of CPT-II $(p=0.01)$. In respect of FAST total score, partial correlations displayed strong relationships between poorer psychosocial functioning and a worsening of cognition. Interestingly, some of the neuropsychological tests (TMT-B, hit reaction time of CPT-II, immediate and delayed recall of CLVT and Stroop inhibition) that were more impaired at $\mathrm{T} 2$ also correlated with worse cognitive and occupational areas and total score of the FAST.

\section{Discussion}

The present findings show that the cognitive functioning of euthymic bipolar patients remains, on average, steadily affected in 6 years of follow-up. Interestingly, psychosocial impairment was more evident in those patients showing a neuropsychological decline. The cognitive domains found to be affected in the present study (executive functioning, inhibition, processing speed and verbal memory) are in congruence with the reported data in recent meta-analyses (Robinson et al. 2006; Torres et al. 2007; Mur et al. 2008; Arts et al. 2008; Bora et al. 2009; Kurtz \& Gerraty, 2009). Furthermore, our results indicate that these particular cognitive domains are linked with psychosocial functioning.

As has already been mentioned, there are very few data regarding follow-up studies on neurocognition in bipolar disorder (Robinson \& Ferrier, 2006; MannWrobel et al. 2011). Our investigation had a unique design because the cognitive performance was assessed at two time points in a 6-year period of followup in euthymic bipolar patients and in the same healthy controls. Indeed, only five longitudinal studies on bipolar disorder and neurocognition have been published so far. Among these previous studies, four of them detected persistent cognitive impairment along time (Engelsmann et al. 1988; Balanzá-Martínez et al. 2005; Mur et al. 2008; Tabarés-Seisdedos et al. 2008), whereas one of them (Burdick et al. 2006) reported that executive and memory functioning suffered more variations over time.

In the present study, extending the re-examination until 6 years has demonstrated that cognitive dysfunction persists even during longer periods of clinical remission. What is more relevant, however, is that the changes in cognitive performance in 6 years affect directly the psychosocial adaptation of these patients as observed in the correlations with the FAST (Rosa et al. 2007). In particular, the areas that appear to be associated with the neuropsychological changes were the cognitive and occupational areas of the FAST. This latter area deserves a comment, since patients with 


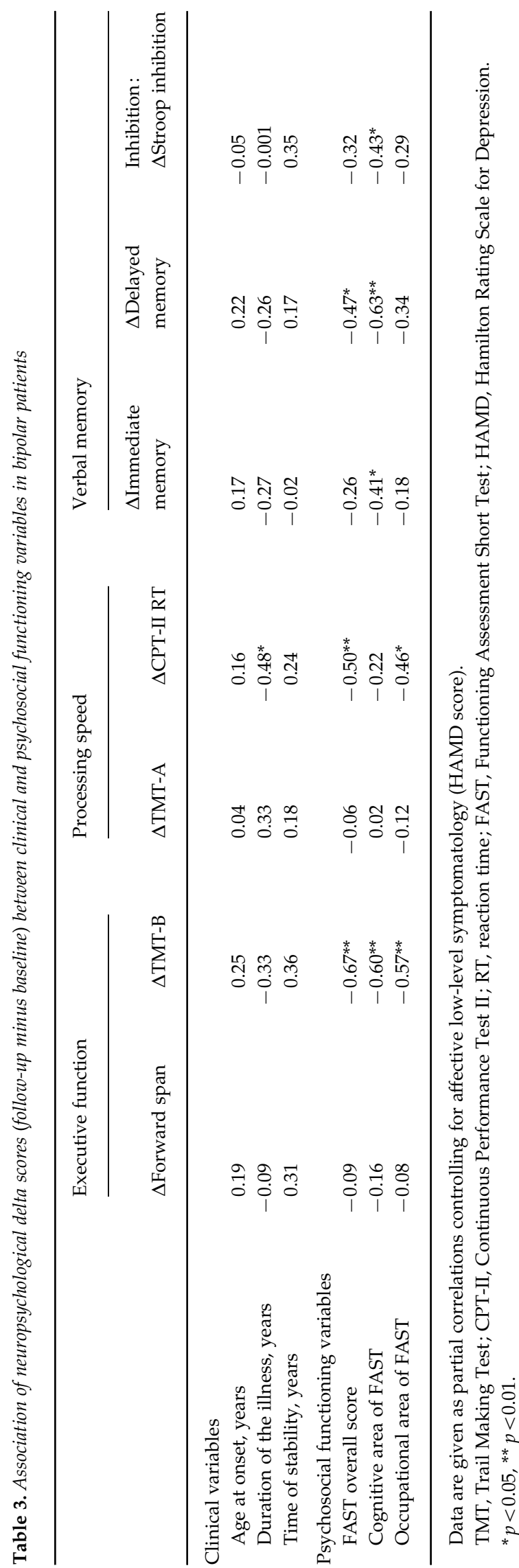

bipolar disorder tend to have high rates of unemployment (Dean et al. 2004; Mur et al. 2009), and it may reflect the impact of the disorder on the psychosocial adaptation of patients. In this regard, previous studies have reported that unemployment would be particularly impaired in those with processing speed deficits (Mur et al. 2008) or with attention deficits (O'Shea et al. 2010).

Previous longitudinal studies evaluating clinical and neurocognitive predictors of functional outcome by means of the FAST (Martino et al. 2009; Bonnín et al. 2010) or other scales (Burdick et al. 2010) have demonstrated the strong relationship of neuropsychological performance and the daily functioning of patients. The cognitive variables that appeared to be related with poor functional outcome were processing speed (Burdick et al. 2010), verbal memory and executive functions (Bonnín et al. 2010), and verbal memory and attention (Martino et al. 2009). However, the neuropsychological performance of patients in these studies was obtained only once, and was used as a predictor of psychosocial adaptation, so the actual impact of cognitive changes on functioning could not be evaluated. This present study suggests that patients with changes in some cognitive domains (executive function, inhibition domain, processing speed and verbal memory) also exhibited poorer psychosocial functioning.

The linkage between clinical variables of severity and cognitive impairment has been evaluated in several studies in terms of age at illness onset (Bora et al. 2009), age (Arts et al. 2008; Gildengers et al. 2009), number of episodes (Robinson \& Ferrier, 2006), years of stabilization and psychotic symptoms (Bora et al. 2007; Mann-Wrobel et al. 2011). In our study the only relevant clinical variable related to cognitive impairment was illness duration, where the longer the duration of illness the slower the processing speed. In the same line as other studies, analysing the moderator effect of aspects of illness progression is imprecise and not well defined.

The presumable impact of psychopharmacological treatment on cognitive dysfunction was not directly assessed because it was not the primary aim of the study. Medication can be a confounder (Robinson et al. 2006) and can have a negative impact on cognitive performance; effects on psychomotor speed have been described (Bora et al. 2009). Nonetheless, cognitive deficits are still evident in euthymic medication-free patients (Goswami et al. 2006) and our sample was not excessively medicated (two or fewer drug classes for most of them), which possibly may have reduced the effect on cognition (Donaldson et al. 2003; MartínezArán et al. 2005). Moreover, a previous study (LópezJaramillo et al. 2010) reported minimal effects of lithium on cognitive performance. 
In spite of the growing number of studies about neurocognition in bipolar disorder, the neurobiological underpinnings of bipolar disorder remain unknown (Berk et al. 2011). The present study helps to elucidate the evolution of cognitive dysfunction in a sample of patients with bipolar disorder. The reported stability of cognitive impairment in the mid-late stages of the illness may contrast with recent evidence which supports the notion of neuroprogressive changes over time (Moorhead et al. 2007; Kauer-Sant'Anna et al. 2009; Berk et al. 2011). Our results are not completely inconsistent with this hypothesis because at the same time that the cognitive deficit persists across time in our sample, the findings also point out that a longer duration of illness is related to progressive changes associated with the illness itself. Future studies focused on cognition in unaffected first-degree relatives, drug-naive patients, early and late stage in bipolar disorder or on measurement of neurobiological biomarkers could answer the question of whether cognitive impairment is a part of neurodevelopmental abnormalities and clarify the pathophysiology and the links between cognitive dysfunction and disease progression (Dias et al. 2009; Kapczinski et al. 2011).

Some limitations warrant acknowledgement in the current study. First, the sample size is relatively small and there is a need of replication with larger samples; even though this is an extended follow-up of a sample published elsewhere (Mur et al. 2008), it is worth mentioning that the drop-out rate at 6 years later was only $15 \%$. An additional weakness of this extended follow-up is that some of the key demographics were not matched any more (e.g. estimated pre-morbid IQ which was included as a covariate). Second, this considerably homogeneous sample with low rates of recurrence might not be representative of the majority of bipolar patients, being biased to patients with better outcomes (Maj et al. 1998; Goodwin \& Vieta, 2005). However, the good clinical outcome of our sample has allowed us to demonstrate the continuity of neuropsychological deficits across a long period of time. Finally, our sample included both bipolar I and II patients; the sample size did not allow enough statistical power to conduct separate analyses for the two groups, but previous studies have reported similar rates of cognitive dysfunction and disability in both subtypes (Rosa et al. 2010; Solé et al. 2011, 2012).

In conclusion, cognitive performance is impaired in euthymic bipolar patients and this deficit remains stable on average over time. In spite of this, there was individual variability where some patients displayed a greater neuropsychological decline, which was associated with a poorer psychosocial adaptation at the end of the follow-up. This finding endorses the fact that longitudinal studies are needed to shed more light on the relative progression of cognitive impairment in subjects with bipolar disorder (Mann-Wrobel et al. 2011). The results of the follow-up studies provide clues about the disease process involved as they may contribute to the development of psychosocial and neuropsychological programmes for improving the currently low functional recovery rates in treated bipolar disorder patients (Gildengers et al. 2009; Martínez-Arán et al. 2011).

\section{Acknowledgements}

This study was financially supported by the following: a Fundació Marató de TV3 Grant (15231/01); an IRBLleida (Biomedicine Research Institute) Contest for a research project for Medical Registers (P10062); and a Spanish FIS-MSC Grant (PI11/01956). M.J.P. is funded by the Ministerio de Ciencia e Innovación of the Spanish Government and by the Instituto de Salud Carlos III through a 'Miguel Servet' research contract (no. CP10-00393), co-financed by the European Regional Development Fund (ERDF) (no. 2007-2013).

We thank the staff of the Department of Psychiatry of Hospital Santa Maria, Lleida; the neuropsychologist, Núria Vidal; and also thank the patients and healthy controls who participated in the study for their kind cooperation.

\section{Declaration of Interest}

E.V. has received research grants and served as consultant, advisor or speaker for the following companies: Almirall, AstraZeneca, Bristol-Myers Squibb, Eli Lilly, Forest Research Institute, Geodon Richter, Glaxo-Smith-Kline, Janssen-Cilag, Jazz, Lundbeck, Merck, Novartis, Organon, Otsuka, Pfizer Inc., SanofiAventis, Servier, Solvay, Schering-Plough, Takeda, United Biosource Corporation, and Wyeth. E.V. has received research funding from the Spanish Ministry of Science and Innovation, the Stanley Medical Research Institute and the 7th Framework Programme of the European Union.

\section{References}

Arts B, Jabben N, Krabbendam L, van Os J (2008). Meta-analyses of cognitive functioning in euthymic bipolar patients and their first-degree relatives. Psychological Medicine 38, 771-785.

Balanzá-Martínez V, Tabarés-Seisdedos R, Selva-Vera G, Martínez-Arán A, Torrent $C$, Salazar-Fraile J, Leal-Cercós C, Vieta E, Gómez-Beneyto M (2005). Persistent cognitive dysfunctions in bipolar I disorder and 
schizophrenic patients: a 3-year follow-up study. Psychotherapy and Psychosomatics 74, 113-119.

Berk M, Kapczinski F, Andreazza AC, Dean OM, Giorlando F, Maes M, Yucel M, Gama CS, Dodd S, Dean B, Magalhaes PV, Amminger P, McGorry P, Malhi GS (2011). Pathways underlying neuroprogression in bipolar disorder: focus on inflammation, oxidative stress and neurotrophic factors. Neuroscience and Biobehavioral Reviews 35, 804-817.

Bonnín CM, Martínez-Arán A, Torrent C, Pacchiarotti I, Rosa AR, Franco C, Murru A, Sanchez-Moreno J, Vieta E (2010). Clinical and neurocognitive predictors of functional outcome in bipolar euthymic patients : a long-term, followup study. Journal of Affective Disorders 121, 156-160.

Bora E, Vahip S, Akdeniz F, Gonul AS, Eryavuz A, Ogut M, Alkan M (2007). The effect of previous psychotic mood episodes on cognitive impairment in euthymic bipolar patients. Bipolar Disorders 9, 468-477.

Bora E, Yucel M, Pantelis C (2009). Cognitive endophenotypes of bipolar disorder: a meta-analysis of neuropsychological deficits in euthymic patients and their first-degree relatives. Journal of Affective Disorders 113, 1-20.

Burdick KE, Goldberg JF, Harrow M (2010). Neurocognitive dysfunction and psychosocial outcome in patients with bipolar I disorder at 15-year follow-up. Acta Psychiatrica Scandinavica 122, 499-506.

Burdick KE, Goldberg JF, Harrow M, Faull RN, Malhotra AK (2006). Neurocognition as a stable endophenotype in bipolar disorder and schizophrenia. Journal of Nervous and Mental Diseases 194, 255-260.

Clark L, Iversen SD, Goodwin GM (2002). Sustained attention deficit in bipolar disorder. British Journal of Psychiatry 180, 313-319.

Conners C (2000). Conners' Continuous Performance Test II Manual. Multi-Health Systems Inc.: Toronto.

Dean BB, Gerner D, Gerner RH (2004). A systematic review evaluating health-related quality of life, work impairment, and healthcare costs and utilization in bipolar disorder. Current Medical Research Opinion 20, 139-154.

Delis DC, Kramer JH, Kaplan E, Ober BA (1987). The California Verbal Learning Test Manual. Psychological Corp.: New York, NY.

Dias VV, Brissos S, Frey BN, Andreazza AC, Cardoso C, Kapczinski F (2009). Cognitive function and serum levels of brain-derived neurotrophic factor in patients with bipolar disorder. Bipolar Disorders 11, 663-671.

Donaldson S, Goldstein LH, Landau S, Raymont V, Frangou S (2003). The Maudsley Bipolar Disorder Project: the effect of medication, family history, and duration of illness on IQ and memory in bipolar I disorder. Journal of Clinical Psychiatry 64, 86-93.

Engelsmann F, Katz J, Ghadirian AM, Schachter D (1988). Lithium and memory: a long-term follow-up study. Journal of Clinical Psychopharmacology 8, 207-212.

Gildengers AG, Mulsant BH, Begley A, Mazumdar S, Hyams AV, Reynolds III CF, Kupfer DJ, Butters MA (2009). The longitudinal course of cognition in older adults with bipolar disorder. Bipolar Disorders 11, 744-752.
Goodwin G, Vieta E (2005). Effective maintenance treatment - breaking the cycle of bipolar disorder. European Psychiatry 20, 365-371.

Goswami U, Sharma A, Khastigir U, Ferrier IN, Young AH, Gallagher P, Thompson JM, Moore PB (2006). Neuropsychological dysfunction, soft neurological signs and social disability in euthymic patients with bipolar disorder. British Journal of Psychiatry 188, 366-373.

Hamilton M (1960). A rating scale for depression. Journal of Neurology, Neurosurgery, and Psychiatry 23, 56-62.

Heaton R (1981). The Wisconsin Card Sorting Test Manual. Psychological Assessment Resources: Odessa, TX.

Kapczinski F, Dal-Pizzol F, Teixeira AL, Magalhaes PV, Kauer-Sant'Anna M, Klamt F, Moreira JC, de Bittencourt Pasquali MA, Fries GR, Quevedo J, Gama CS, Post R (2011). Peripheral biomarkers and illness activity in bipolar disorder. Journal of Psychiatry Research 45, 156-161.

Kauer-Sant'Anna M, Kapczinski F, Andreazza AC, Bond DJ, Lam RW, Young LT, Yatham LN (2009). Brainderived neurotrophic factor and inflammatory markers in patients with early- vs. late-stage bipolar disorder. International Journal of Neuropsychopharmacology 12, 447-458.

Kurtz MM, Gerraty RT (2009). A meta-analytic investigation of neurocognitive deficits in bipolar illness: profile and effects of clinical state. Neuropsychology 23, 551-562.

López-Jaramillo C, Lopera-Vásquez J, Ospina-Duque J, García J, Gallo A, Cortez V, Palacio C, Torrent C, Martínez-Arán A, Vieta E (2010). Lithium treatment effects on the neuropsychological functioning of patients with bipolar I disorder. Journal of Clinical Psychiatry 71, 1055-1060.

Maj M, Pirozzi R, Magliano L, Bartoli L (1998). Long-term outcome of lithium prophylaxis in bipolar disorder: a 5year prospective study of 402 patients at a lithium clinic. American Journal of Psychiatry 155, 30-35.

Mann-Wrobel MC, Carreno JT, Dickinson D (2011). Metaanalysis of neuropsychological functioning in euthymic bipolar disorder : an update and investigation of moderator variables. Bipolar Disorders 13, 334-342.

Martínez-Arán A, Torrent C, Solé B, Bonnín CM, Rosa AR, Sánchez-Moreno J, Vieta E (2011). Functional remediation for bipolar disorder. Clinical Practice and Epidemiology in Mental Health 7, 112-116.

Martínez-Arán A, Vieta E, Colom F, Torrent C, Reinares M, Goikolea JM, Benabarre A, Comes M, Sánchez-Moreno J (2005). Do cognitive complaints in euthymic bipolar patients reflect objective cognitive impairment? Psychotherapy and Psychosomatics 74, 295-302.

Martínez-Arán A, Vieta E, Colom F, Torrent C, Sánchez-Moreno J, Reinares $M$, Benabarre $A$, Goikolea JM, Brugué E, Daban C, Salamero M (2004a). Cognitive impairment in euthymic bipolar patients: implications for clinical and functional outcome. Bipolar Disorders 6, 224-232.

Martínez-Arán A, Vieta E, Reinares M, Colom F, Torrent C, Sánchez-Moreno J, Benabarre A, Goikolea JM, Comes M, Salamero M (2004b). Cognitive function across manic or 
hypomanic, depressed, and euthymic states in bipolar disorder. American Journal of Psychiatry 161, 262-270.

Martino DJ, Marengo E, Igoa A, Scapola M, Ais ED, Perinot L, Strejilevich SA (2009). Neurocognitive and symptomatic predictors of functional outcome in bipolar disorders: a prospective 1 year follow-up study. Journal of Affective Disorders 116, 37-42.

Meyers JE, Meyers KR (1995). Rey Complex Figure Test and Recognition Trial. Psychological Assessment Resources: Odessa, FL.

Moorhead TW, McKirdy J, Sussmann JE, Hall J, Lawrie SM, Johnstone EC, McIntosh AM (2007). Progressive gray matter loss in patients with bipolar disorder. Biological Psychiatry 62, 894-900.

Mur M, Portella MJ, Martínez-Arán A, Pifarré J, Vieta E (2007). Persistent neuropsychological deficit in euthymic bipolar patients : executive function as a core deficit. Journal of Clinical Psychiatry 68, 1078-1086.

Mur M, Portella MJ, Martínez-Arán A, Pifarré J, Vieta E (2008). Long-term stability of cognitive impairment in bipolar disorder: a 2-year follow-up study of lithiumtreated euthymic bipolar patients. Journal of Clinical Psychiatry 69, 712-719.

Mur M, Portella MJ, Martinez-Aran A, Pifarre J, Vieta E (2009). Influence of clinical and neuropsychological variables on the psychosocial and occupational outcome of remitted bipolar patients. Psychopathology 42, 148-156.

O'Shea R, Poz R, Michael A, Berrios GE, Evans JJ, Rubinsztein JS (2010). Ecologically valid cognitive tests and everyday functioning in euthymic bipolar disorder patients. Journal of Affective Disorders 125, 336-340.

Reitan R (1958). Validity of the Trail Making Test as an indicator of organic brain damage. Perceptual and Motor Skills 8, 271-276.

Robinson LJ, Ferrier IN (2006). Evolution of cognitive impairment in bipolar disorder: a systematic review of cross-sectional evidence. Bipolar Disorders 8, 103-116.

Robinson LJ, Thompson JM, Gallagher P, Goswami U, Young AH, Ferrier IN, Moore PB (2006). A meta-analysis of cognitive deficits in euthymic patients with bipolar disorder. Journal of Affective Disorders 93, 105-115.

Rosa AR, Bonnín CM, Vázquez GH, Reinares M, Solé B, Tabarés-Seisdedos R, Balanzá-Martínez V, González-Pinto A, Sánchez-Moreno J, Vieta E (2010).
Functional impairment in bipolar II disorder: is it as disabling as bipolar I? Journal of Affective Disorders 127, $71-76$.

Rosa AR, Sánchez-Moreno J, Martínez-Aran A, Salamero M, Torrent C, Reinares M, Comes M, Colom F, Van Riel W, Ayuso-Mateos JL, Kapczinski F, Vieta E (2007). Validity and reliability of the Functioning Assessment Short Test (FAST) in bipolar disorder. Clinical Practice and Epidemiology in Mental Health 3, 5.

Savitz J, Solms M, Ramesar R (2005). Neuropsychological dysfunction in bipolar affective disorder : a critical opinion. Bipolar Disorders 7, 216-235.

Solé B, Bonnin CM, Torrent C, Balanzá-Martinez V, Tabarés-Seisdedos R, Popovic D, Martínez-Arán A, Vieta E (2012). Neurocognitive impairment and psychosocial functioning in bipolar II disorder. Acta Psychiatrica Scandinavica 125, 309-317.

Solé B, Martínez-Aran A, Torrent C, Bonnin CM, Reinares M, Popovic D, Sánchez-Moreno J, Vieta E (2011). Are bipolar II patients cognitively impaired? A systematic review. Psychological Medicine 41, 1791-1803.

Spreen O, Strauss E (1998). A Compendium of Neuropsychological Tests. Oxford University Press: New York.

Tabarés-Seisdedos R, Balanzá-Martínez V, SanchezMoreno J, Martinez-Aran A, Salazar-Fraile J, Selva-Vera G, Rubio C, Mata I, Gómez-Beneyto M, Vieta E (2008). Neurocognitive and clinical predictors of functional outcome in patients with schizophrenia and bipolar I disorder at one-year follow-up. Journal of Affective Disorders 109, 286-299.

Torres IJ, Boudreau VG, Yatham LN (2007). Neuropsychological functioning in euthymic bipolar disorder: a meta-analysis. Acta Psychiatrica Scandinavica Supplementum, issue 434, 17-26.

Wechsler D (2001). Wechsler Adult Intelligence Scale-III: Technical Manual (Spanish Version). TEA: Madrid.

Wingo AP, Harvey PD, Baldessarini RJ (2009). Neurocognitive impairment in bipolar disorder patients: functional implications. Bipolar Disorders 11, 113-125.

Young RC, Biggs JT, Ziegler VE, Meyer DA (1978). A rating scale for mania: reliability, validity and sensitivity. British Journal of Psychiatry 133, 429-435. 